\title{
An Upscaling Technique for Production Forecasting of Gas Recycling in a Near - Miscible Oil Reservoir
}

\author{
Hanssen M. M., Hove $\mathbf{K}$.
}

Norsk Hydro a. s., Norway

\begin{abstract}
Copyright 1995. Steering Committee of the European IOR - Symposium.
This paper was presented at the Bth. European IOR - Symposium in Vienna, Austria, May 16 - 17, 1985

This paper was selected for presentation by the Steering Committee, following review of information contained in an abstract

submitted by the author(s). The paper, as presented has not been reviewed by the Steering Committee.
\end{abstract}

\begin{abstract}
ARSTRACT
This paper describes a method used for scaling black oil production profiles in order to account for compositional effects taking place duning a gas recycling scheme in a near miscible reservoir. The procedure has successfully been used for the Njord Field offshore mid-Norway.
\end{abstract}

The Njord Field is a sandstone reservoir with an undersaturated, near miscible oil. The more prolific part of the reservoir is to be developed by re-injecting separator gas updip into the structure, while a smaller, highly faulted part of the reservoir will be developed under depletion. The reservoir is highly compartmentalized and by carefully allocating the available injection gas volume, partial pressure maintenance and near miscible conditions can be obtained. Even though the displacement process will remain immiscible, compositional effects will be present in the form of (1) swelling, when the oil is contacted with the dry injection gas and (2) stripping of intermediate components from the oil. The mass transfer processes represent an important IOR potential.

To properly evaluate the mass transfer benefits, identical compositional and black oil reservoir simulations of gas injection into an isolated reservoir segment were compared The results were used to construct dimensionless curves that were used for scaling up the full field black oil production profiles in order to account for compositional effects on the Njord Field. The black oil results were scaled based on (1) recycled gas volume expressed in terms of associated volume of gas initially in place and (2) degree of pressure maintenance obtained expressed as minimum reservoir pressure during production.
The full field production profile for the Njord Field based on this upscaling technique, was later verified against a full field compositional reservoir simulation model.

Incorporating the results from the compositional simulations in the full field production forecasts proved to be important for the Njord Field. Including compositional effects in the production profiles influenced on the reservoir management plan for the field and was important for optimisation of the field gas handling capacity.

\section{INTRODUCTION}

The Njord Field is located $120 \mathrm{~km}$ west of the Norwegian cost in the Haltenbanken Area, Figure 1. The field was discovered by the $6407 / 7-1$ well in 1986 , followed by four appraisal wells between 1987 and 1991. The Njord Field was declared commercial in 1994, with $31.6 \mathrm{MSm}^{3}$ oil reserves, but with an expected low rate of return on initial investments the field must be considered marginal. Expected production start-up is October 1997.

Oil has been found in three Jurassic sandstone reservoirs with the main reservoir being the Tilje Formation. The field is planned developed with 15 highly deviated or horizontal wells, Figure 2. The field is divided into three areas; (1) The East Flank with a 400 meter thick oil column and good reservoir quality. The East Flank will be developed with gas re-injection as the main drive mechanism. (2) The Central Area located on the crest of the structure is more faulted and has poorer reservoir quality than the East Flank. Due to uncertainties concerning communication across the faults, depletion has been chosen as initial drive mechanism for most of the Central Area segments. (3) The Northern Area is 
highly faulted and has poor reservoir quality. The Northern Area has not been included in the target area for the field, but may be tied in to the platform at a later stage.

The Minimum Miscibility Pressure, MMP, with separator gas for the oil contained in the more prolific East Flank is approximately 400 bar while the initial reservoir pressure is 390 bar. The East Flank oil may therefore be classified as near miscible at initial reservoir conditions.

The objective of this study was to generate production forecasts for the Njord Field which included the mass transfer processes expected to take place in the reservoir during the gas recycling displacement process at near-miscible conditions. A conventional black oil simulator is incapable of modeling these processes and will consequently predict too low recoveries for these type of production schemes.

It was therefore neccessary to build a compositional model in order to study the effect of gas re-injection into the East Flank. By comparing the result from this model with the results from an identical black oil model, the effects of the mass transfer processes, hereafter called compositional effects, could be isolated from other displacement mechanisms and thus quantified. Due to the high CPU cost associated with current commercial compositional simulators, a small sector model was used for evaluating the compositional effects. The main challenge was therefore to scale the full field black oil simulation profiles based on results from the sector model simulations.

The work was divided into four tasks:

- Develop a fluid characterization for compositional simulation.

- Perform a qualitative study of the compositional displacement process in a small sector model.

- Quantify the compositional effects and if possible define a functional relationship between predicted recovery in a black oil model and a compositional model.

- Scale the full field black oil production profiles for the Njord Field to include the compositional effects.

\section{ELUID BEHAVIORAND CHARACTERIZATION}

\section{Fluid distribution and parameters}

The two separate parts of the target area of the Njord Field contain incompatible but similar undersaturated volatile or light oils. Two exploration wells have penetrated the East Flank. The first well $(6407 / 7-1)$ came in high on the structure and the collected oil samples contained an undersaturated $\left(\mathrm{P}_{b 0}=310\right.$ bara, $\mathrm{P}_{\mathrm{i}}=390$ bara @ $\left.2850 \mathrm{~m} \mathrm{MSL}\right)$ volatile oil with solution gas-oil-ratio of $243 \mathrm{Sm}^{3} / \mathrm{Sm}^{3}$ $\left(\mathrm{GOR}_{\mathrm{s}}\right)$ and formation volume factor of $1.74 \mathrm{Rm}^{3} / \mathrm{Sm}^{3}$ $\left(\mathrm{B}_{\text {oif }}\right)$.

When the second well $(6407 / 7-4)$ showed a slightly heavier oil $\left(\mathrm{GOR}_{\mathrm{sf}}=202 \mathrm{Sm}^{3} / \mathrm{Sm}^{3}, \mathrm{~B}_{\text {ois }}=1.60 \mathrm{Rm}^{3} / \mathrm{Sm}^{3}, \mathrm{P}_{\mathrm{tp}}=289\right.$ bara), it was assumed to be due to the existence of a compositional gradient in the reservoir. The $6407 / 7-4$ well is located approximately 100 meters downflank to and also further southwest of the $6407 / 7-1$ well. Whether the difference in fluid properties are due to areal or vertical compositional gradients (or both) remains uncertain. The compatibility of the obtained fluid samples from the two wells on the East Flank was tested by use of compositional gradient theory, Ref. $\mid 1 \backslash$ and Ref. $12 \backslash$. The test showed that the variations may be explained as the result of a vertical gradient if some thermal diffusion is assumed to be present in the reservoir.

The Central Area contains a less volatile incompatible black oil with a GOR of $204 \mathrm{Sm}^{3} / \mathrm{Sm}^{3}$ and a $B_{\text {ois }}$ of $1.64 \mathrm{Rm}^{3} / \mathrm{Sm}^{3}$. The bubble point pressure is 302 bara which is 80 bar below initial reservoir presssure.

The large volumes of associated gas in the Njord Field may represent a significant gas handling problem for a field development since no gas export solution presently exists for the area. Re-injection is therefore the only feasible alternative if the field is to be exploited economically in the near future.

\section{Fluid Characterization}

The first step in the compositional simulation study was to develop a fluid characterization for compositional simulation. The characterization was based on available PVT studies and the crude oil characterization of a $6407 / 7-4$ bottomhole sample. The recommended composition given in Figure 3 was used as input to the characterization process, using the Peng-Robinson, Ref. $|3|$, equation of state in the PVT-package PVTx, Ref. 121. The liquid density calculations were based on the equation of state including the volume translation option. Figure 3 gives a schematic overview of the characterization process.

A series of fluid characterizations was developed by use of different tuning parameters, all giving good match to the conventional PVT data. But, when tested in the slimtube simulator, they either predicted a too high MMP or underestimated the slope of the recovery versus injection pressure curve. The final characterization was selected due to its excellent match of swelling test results and good agreement with slimtube results. Figure 3 shows how the initial 19 component characterization was successfully lumped to a 7 pseudo-component characterization. Figure 4 shows the resulting match between the calculated PVT values and the experimental test results.

The match of the swelling experiment was given special attention since this was the only experiment which could be included in the regression basis and which described a dynamic reservoir process. The resuits slightly underpredict the swelled volume while the calculated saturation pressures are a bit too high at high injected GOR values. Overall the match to the swelling test agrees almost perfectly with the experimental data.

The slim tube experiment could not be included in the basis for the regression routine when using the automatic PVT-package. The different characterizations were ran on a slim tube simulator. Oil recovery at 1.2 pore volume of gas injected $\left(\mathrm{PV}_{\mathrm{inj}}\right)$ was plotted as a function of injection pressure and compared to experimental data. A common problem for the characterizations was that no defined break over point could be identified on the curve. The break over point, the point at which the increase in recovery is marginal if the pressure increased further, defines the MMP for the mixed vaporization process $\left(\mathrm{MMP}_{\text {mix }}\right)$, also called the true MMP. A mixed vaporization process means that there is transfer of components both from the injection gas to the reservoir oil and from the oil to the free gas phase. This is 
believed to be the type of miscible displacement taking place during gas injection into the East Flank.

$100 \%$ recovery was obtained in the slim tube model and can be taken as an indication of the minimum miscibility pressure for the purely vaporizing process, $\mathrm{MMP}_{\mathrm{vgd}} \mathrm{MMP}_{\operatorname{mix}}$ will always be lower than $M M P_{\text {ved, }}$ Ref. $|4|$, and the difference can typically be 20 to 30 bar. Figure 5 , which shows the simulated slim tube results plotted together with the experimental data, indicates a $\mathrm{MMP}_{\mathrm{vgd}}$ around 425 bar (dispersion free). Recoveries above $90 \%$ are obtained for injection pressures higher than 390 bar. The true minimum miscibility pressure predicted by the developed fluid characterization should therefore be between 390 and 425 bar.

The $\mathrm{MMP}_{\text {true }}$ identifed in the slim tube test was 394 bar.

\section{SECTOR MODEL SIMULATIONS}

\section{The Compositional and the Black Oil Sector Models}

The next step in the compositional simulation study was to construct identical black oil and compositional sector models which could be used for sensitivity simulations. And later, if possible define a functional relationship between the recoveries obtained from compositional simulations and from black oil simulations.

The E4 segment, Figure 2, contains almost $50 \%$ of the recoverable resources on the East Flank and it was therefore natural to choose this segment for this study.

MORE, Ref. $15 \backslash$, is the compositional simulator presently used by Norsk Hydro. ECLipse, Ref. 161 is the conventional black oil simulator used for the existing Njord Field reservoir simulation models. The compositional and the black oil models were constructed as identical models and the main input parameters and the geological input are presented in Table 1 and Figure 6 . However, while the compositional reservoir simulation model was initiated using the 6407/7-4 7-pseudo-component fluid characterisation, assuming no compositional gradient in the reservoir, the black oil model was initiated using black oil PVT data taken from an existing 6407/7-1 characterisation. The ratio of the stock tank oil in place volumes is therefore equal to the inverse ratio of the oil formation volume factors. STOIIP $_{\text {comp }} /$ STOIIP $_{\text {bleck }}=B_{\text {vi } 64077-1)} / \mathrm{B}_{\mathrm{oi}(640774)}$. The associated gas volumes are likewise different due to this difference in STOIIP and the difference in GOR values between the two fluids.

\section{Production Scheme}

The injection gas was assumed to be a mixture of produced separator gas and import gas, produced from other segments in the Njord Field or from external gas sources.

Each simulation case was defined by an upper limit of available import gas rate and by the total gas injection and production capacities. The actual gas import rate is a result of these three parameters and injection and production pressures, equal to 340 bar and 100 bar at the tubing heads, respectively. The location of the wells is shown in Figure 6.

Initial simulations showed that the gas handling capacity was vital for the final recovery. The differences in initial GOR between the compositional and the black-oil models resulted in a difference in real gas constraints. All gas rates in the compositional model were therefore adjusted for the difference in GOR in order to get directly comparable results from the two models.

\section{Compositional Simulation Results}

The compositional simulator was used for a series of runs. Each series is defined by a gas injection rate and a gas production rate. A series contains a set of cases each restricted by different available gas import rates. The first case in each series is the reinjection case where no import gas is available. The last case in each series corresponds to full pressure maintenance where the only restriction is the maximum injection pressure.

Figure 7 shows the production profile for one of the simulated cases.

All the simulated cases behave similariy. The only variations are the specified production and injection constraints and the degree of pressure maintenance. The presented case can therefore serve as an example of the type of simplified displacement process simulated.

The oil production goes off plateau when the first producer experiences a gas breakthrough. The gas will rapidly break through in the highly permeable zones and from then on the production enters a gas recycling scheme.

In this case the available gas import rate is set to $1 \mathrm{MSm}^{3} / \mathrm{d}$. This is not sufficient to provide pressure maintenance and the reservoir pressure declines during the first 3 years. After gas breakthrough, the available import gas volume is sufficient to replace more than the volume of produced oil, and the pressure starts to rebuild. After 10 years the injection is limited by maximum injection pressure.

The compositional effects will for this case be a combination of near miscible behaviour with component exchange between the injection gas and the reservoir oil when the reservoir is at near miscible conditions, swelling of oil by re-solution of free gas and stripping of intermediate hydrocarbon components from the oil by continuous recycling of dry injection gas.

The initial idea was to identify a functional relationship between pressure maintenance and the incremental recovery obtained from compositional effects. The degree of pressure maintenance is best expressed by the minimum reservoir pressure observed. In all cases where import gas is available throughout the production period, the pressure drops to a minimum before the segment is re-pressurized. If no import gas is available, or if additional gas volumes are available for a limited period only, the pressure declines continuously and the minimum pressure is equal the to pressure in the segment at the end of production. When plotting recovery versus minimum reservoir pressure for all compositional simulation series, Figure 8 , it is evident that recovery increases with pressure, at least if compositional effects are included in the recovery estimate. A distinct increase in recovery can be seen as the pressure is kept above bubble point. Above saturation pressure, as the pressure approaches minimum miscibility pressure, recovery increases steadily.

However, the results clearly show that the highest recoveries are obtained if a high degree of pressure maintenance is combined with a high level of gas recycling. This is possible if the gas handling capacity is large. Clearly, final recovery 
is improved by recycling larger volumes of gas through the reservoir. This is because of the stripping effect where intermediate hydrocarbon components are vaporised by continuous exposure to dry injection gas.

Figure 8 summarises how the different production parameters influence the final recovery.

One series is defined by equal gas injection and production rate. If maximum injection rate is kept equal to maximum production rate it is only until gas breakthrough that pressure maintenance is possible. However, even the limited period of initial pressure maintenance results in an important increase in recovery compared to re-injection.

\section{Compositional Simulation Results versus Black Oil} Simulation Results

Figure 9 shows production profiles from identical compositional and black oil simulations plotted together. The oil production profile predicted by the compositional simulator is far superior to the production profile generated by the black oil model.

The difference in the predicted production profiles is partly due to the fact that the black oil model is run under the assumption of no re-solution of free gas in the oil. However, the stripping of intermediate hydrocarbon components from the oil by the dry injection gas results in an oil recovery mechanism which the black oil model is incapable of modelling.

The predicted recoveries from the black oil simulations are plotted as a function of minimum reservoir pressure, Figure 10. When comparing these black oil results to the compositional simulation results, three differences are striking. All the recoveries predicted by the black oil simulation model are lower, even the reinjection cases. Secondly, the black oil simulations show limited gain from increasing the level of pressure maintenance further than keeping the pressure above bubble point. The third difference is that minimum reservoir pressures observed during the compositional simulations are lower than the pressures observed during the corresponding black oil simulation.

\section{Scaling Function for Compositional Effects}

From the cases run parallel on identical compositional and black oil simulation models, a set of comparable results was available. The compositional effects, in terms of recovery, would then be the difference in predicted final recoveries between the two models.

The predicted recoveries for these simplistic cases are shown to be dependent on two identified parameters; the degree of pressure maintenance and the degree of gas recycling taking place during the production period.

Minimum reservoir pressure during production is used as an indication of the degree of pressure maintenance. By plotting the difference in predicted recovery as a function of the black oil predicted minimum pressure, the plot can be used to estimate the marginal increase in recovery which would result from compositional effects for a given black oil simulation.

Different levels of gas recycling were expressed in terms of gas handling capacity. However, the rates used in the sector model simulations were specific for the E4 segment and adjusted for the difference in GOR between the black oil and the compositional model. A specific production period was also used. The volume of produced gas was therefore felt to be a more general parameter for the degree of gas recycling taking place than the gas rate. By expressing the volume of recycled gas in terms of associated gas initially in place 1) the difference in GOR between the compositional model and the black oil model was eliminated and 2) independence of STOIIP and the length of the production period is obtained.

Likewise, for a more general use the compositional effects could not be expressed in terms of marginal recovery. The ratio between the recovery predicted by the compositional model and by the black oil model is independent of recovery level and can therefore be used for any segment in the East Flank Area.

Figure 11 shows the derived functional relationship between the degree of pressure maintenance, the level of gas recycling and the compositional effects in terms of incremental recovery. The figure also shows an example of how the plot can used for scaling black oil simulation results. The predicted recovery obtained from black oil simulation of a gas injection process including a minimum reservoir pressure of 325 bara and a recycled gas volume equal 3.8 times associated GIIPs, should be multiplied with a factor of 1.13 to account for compositional effects.

\section{NJORD FIRID APPLICATIONS}

\section{Scaling Full Field Black Oil Profiles}

A black oil model was used for Njord full field simulations. The main reasons for selecting a black oil model were; (1) lower CPU consumption and (2) limitations in the compositional model with respect to fault modelling and production control. The last step in the generation of production forecasts for the Njord Field which included an estimate of compositional effects, was therefore to scale the full field black oil production profiles based on the sector model simulation study.

The scaling procedure consisted of three steps. First the full field black oil model was run. Secondly, the minimum reservoir pressure for the East Flank was calculated as the volume weighted average of the minimum pressures observed on the East Flank. Likewise, the dimensionless gas cycling parameter was calculated using the total produced gas volume and the associated GIIP contained on the East Flank. These two parameters were then used to obtain a scaling factor (from Figure 11) for the compositional effects. Finally, the black oil full field production profile and the scaling factor for the East Flank was input to an in-house production planning program. A full field production forecast including the estimated compositional effects was thereby attained.

Due to the field oil capacity limitations, the individual well profiles could only be increased after the field had gone off plateau. This is, however, in agreement with the observation from the production profiles from the compositional and the black oil models which showed only a limited increase in plateau length, Figure 9. In Figure 12 the scaled and unscaled black oil full field profiles are shown. 


\section{Reservoir Management Aspects}

The compositional simulations study revealed two phenomena which had major impact on the production planning; (1) a large increase in the compositional effects above bubble point pressure, and (2) importance of circulating large gas volumes when optimizing the compositional effects.

Prior to the compositional study only the East Flank was included in the target area. The minimum reservoir pressure was then 60 bar below the bubble point. The field's total gas capacity was also limited to $6 \mathrm{MSm}^{3} / \mathrm{sd}$. To be able to maximise the beneficial compositional effects the reservoir management on Njord was re-evaluated. Three main issues were re-evaluated:

- the base case production area

- the phasing-in of the different production areas

- the field total gas production capacity

In order to increase the degree of pressure maintenance the base case target area was extended to also include the highly fauited Central Area. By developing this area after the East Flank the produced gas can be used for injecting and thereby increasing the minimum reservoir pressure in the East Flank segments with 60 bar, Figure 13.

However, as can be seen from Figure 13, there is a large decline in the reservoir pressure before produced gas from the Central Area is available for injection. By phasing in the Central Area even earlier compared to the East Flank, the minimum reservoir pressure could be increased with an additional 30 bar, Figure 13. Due to the low expected production rates from the Central Area wells, only a limited number of these wells can be justified drilled before plateau production is established. By including the Central Area in the target area and phasing it in parailel to the East Flank, the minimum reservoir pressure was increased with as much as 90 bar and thereby increasing the compositional effects considerably. With a field gas capacity of $6 \mathrm{MSm}^{3} / \mathrm{d}$ the field reserves was increased with $8 \%$, Figure 14

An cost-benefit anaiysis was performed on the field gas capacity. As can be seen from Figure 11, oil recovery increases with increasing gas capacity. Based on the cost-benefit analysis a field gas capacity of $10 \mathrm{MSm}^{3} / \mathrm{d}$ was chosen. This increased the field reserves with an additional $14 \%$, Figure 15 . Increasing the gas handling capacity on the Njord Field had only minor impact on the topside facilities and thereby the development costs. However, if the gas handling capacity had been changed after the field had been developed, the associated cost could have been larger. This shows the importance of early evaluation of the compositional effects for optimising the reservoir management for the field.

If compositional effects are not included in the production forecasts, no benefit can be seen on the East Flank reserves when including the Central Area and only an $8 \%$ increase in reserves was attained if increasing the gas capacity from 6 $\mathrm{MSm}^{3} / \mathrm{d}$ to $10 \mathrm{MSm}^{3} / \mathrm{d}$. This clearly illustrates the importance of including the compositional effects when evaluating the optimal gas injection scheme.

The optimisation of the reservoir management of the Njord Field has been important for attaining an acceptable rate of return from the project and the results from the compositional simulation studies have been important to assure an optimal recovery from the field. Based on the results from the compositional simulation study and the optimisation of the reservoir management the expected reserves from the Njord Field was increased with $26 \%$.

Also when evaluating the optimal drive mechanism for the field the compositional effects are important to model.If the compositional effects are excluded, water and gas reinjection gives almost the same recovery factor. However, if included, gas injection becomes superior to water injection.

\section{DISCUSSION}

The production forecasts presently used for the Njord Field development plans are based on black oil simulations which have been scaled as described above. Including the compositional effects in the production forecast has resulted in an important improvement in the reserve estimate and therefore in the calculated rate of return for the field and has also resulted in an altered reservoir management plan.

The uncertainty connected to the estimated compositional effects can be grouped into two main categories; (1) the uncertainty connected to the input parameters, and (2) the uncertainty connected to the method used to obtain the estimate. The first category is not specific for this study but connected to all reservoir engineering work performed on the Njord Field and will not be treated here. As for the uncertainty connected to the method used, three aspects are discussed

- Validity of the developed scaling method.

- Impact of reservoir characterization on the compositional effects.

- Importance of using an representative sector model.

In order to verify the scaling method a compositional full field model was created. The model is identical to the black oil full-field model except for the PVT input data. The ECLipse 300 simulator, Ref. 19/, was used. The average minimum reservoir pressure in the black oil model was 320 bar and the dimensionless gas cycling number was 4.3. Based on the functional relationship between compositional effects, pressure and recycled gas volume, Figure 11, the scaling factor for the field should be 1.15. The compositional full field simulations gave $15 \%$ higher recovery factor than the black, Figure 16. This indicates that the developed scaling procedure gives acceptable results. This was the case even though the scaling parameters, average minimum reservoir pressure and the dimensional gas cycling number, were calculated based on an average of the different East Flank segments. The decision to use the weighted average values for the East Flank as input to the scaling function was based on the observation that the minimum pressure in each segment was above bubble point. As can be seen from Figure 11 the slope of the scaling curve is almost constant above the bubble point. The distribution of the gas between the different segments is therefore not critical.

An other important aspect when investigating gas injection and the possibility of beneficial compositional effects is to have a reservoir description which is detailed enough to properly model the displacement in the reservoir, Ref. 17 . The number of grid blocks in the vertical direction is important both for modelling the heterogeneities correctly. and to allow for vertical segregation. A detailed stochastic geological model, Ref. 181 , was used to evaluate the impact of geological modelling on the compositional effects. In the 
stochastic model the number of layers was 39 , which gives approximately 2-3 meter thick grid blocks. In Figure 17 a cross section of the simulation model is shown. As can be seen from Table $2 ;$ the detailed stochastic model gave the same compositional effects as the 12 layer model. This indicates that the 12 layer model is sufficiently detailed.

Some uncertainty is connected to the representativity of the selected E4 segment. Since this segment contains approximately $50 \%$ of the recoverable resources on the East Flank the question of representativity is only connected to the other $50 \%$. The dip of the reservoir is believed to be an important parameter when evaluating gas injection schemes. The dip in the E4 segment is similar to the dip in the other segments and this should mean that the contact area between injection gas and reservoir oil is almost the same in all segments. Otherwise, since the heterogeneities are similar and the displacement processes taking place in each segment are almost identical, the decision to use a sector model should be sane.

\section{CONCLUSIONS}

The main conclusions from the compositional simulation study conducted on the Njord Field and its applications to the field's development strategy are:

- Compositional effects will be present in gas recycling production schemes even if the pressure is relative far from miscible conditions.

- Compositional effects increase with the degree of pressure maintenance and with the level of gas recycling.

- Scaling black oil production profile for compositional effects based on a functional relationship derived from sector model simulations proved to give reliable results.

- When including the compositional effects in the production forecasts for the Njord Field the reservoir management plan was re-evaluated.

- Including compositional effects in the production forecasts is important in order to avoid sub-optimization of the development plans.

\section{NOMENCLATURE}

$\begin{array}{ll}\text { B } & \text { - Formation volume factor, } \mathrm{Rm}^{3} / \mathrm{Sm}^{3} \\ \text { CPU } & \text { - Central Processing Unit } \\ \text { GIP } & \text { - Gas initially in place, } \mathrm{Sm}^{3} \\ \text { GOR } & \text { - Gas-oil ratio, } \mathrm{Sm}^{3} / \mathrm{Sm}^{3} \\ \text { MSL } & \text { - Mean sea level, meter } \\ \text { MMP } & \text { - Minimum miscibility pressure, bar } \\ \text { P } & \text { - Pressure; bar } \\ \text { PV } & \text { - Pore volume, } \mathrm{m}^{3} \\ \text { S } & \text { - Saturation, fraction } \\ \text { STOIIP } & \text { - Stock tank oil initially in place, } \mathrm{Sm}^{3}\end{array}$

\section{ACKNOWLEDGEMENT}

The authors would like to thank the PL 107/PL 132 partners, Statoil a.s, Mobil Exploration Norway. Inc: and Deminex Norge a.s, for their approval to publish this paper. The authors would also like to thank all colleagues in Norsk Hydro Exploration and Production Division who have contributed to the results presented in this paper, and to the Njord project and the management of Norsk Hydro a.s. for permission to publish this paper.

\section{REFERENCES}

1. C.H.Whitson and P.Belery, "Compositional Gradients in Petroleum Reservoirs", paper SPE 28000 presented at the 1994 SPE Centennial Petroleum Engineering Symposium, Tulsa, OK, August 29-31

2. PVTx User Manual, Pera a/s, Version 94.02

3. D.Y.Peng and D.B.Robinson,:"A New Two-Constant Equation of State", Ind. Eng. Chem. Fund. (1976) 15, No. 1, 59-64.

4. A.A. Zick,.: "A combined Condensing/Vaporizing Medhanism in the Displacement of Oil by Enriched Gases.", paper SPE 15493 presented at the SPE 61 st Annual Technical Conference and Exhibition, New Orleans, October 1986.

5. MORE User guide, Reservoir Simulation Research Corporation, July 1994.

6. ECLipse 100 Reference Manual, 94A, Intera Information Technology Limited, 1994.

7. F.I.Stalkup,"The Effect of Gas Enrichment and Numerical Dispersion on Compositional Simulator Predictions of Oil Recovery in Reservoir Condensing and Condensiong/Vaporizing Gas Drive", paper SPE 18060 presented at the 1988 Annual Technical Conference and Exhibition of the SPE held in Houston, TX, October 2-5.

8. K.Hove, G.Olsen, S.Nilsson, M.Tønnesen, "From Stochastic Geological Description to Production Forecasting in Heterogenous Layered Reservoir", paper SPE 24890 presented at the 1992 Annual Technical Conference and Exhibition of the SPE held in Washington DC, October 4-7.

9. ECLipse 300 Reference Manual, 94A, Intera Information Technology Limited, 1994.

\section{SUBSCRIPT}

$\begin{array}{ll}\text { bp } & \text { - Bubble point } \\ \mathrm{g} & - \text { Gas } \\ \mathrm{i} & \text { - Initial } \\ \mathrm{o} & \text { - Oil } \\ \text { prod } & \text { - Production } \\ \text { sf } & \text { - Single flash } \\ \text { vgd } & \text { - vaporizing gas drive }\end{array}$




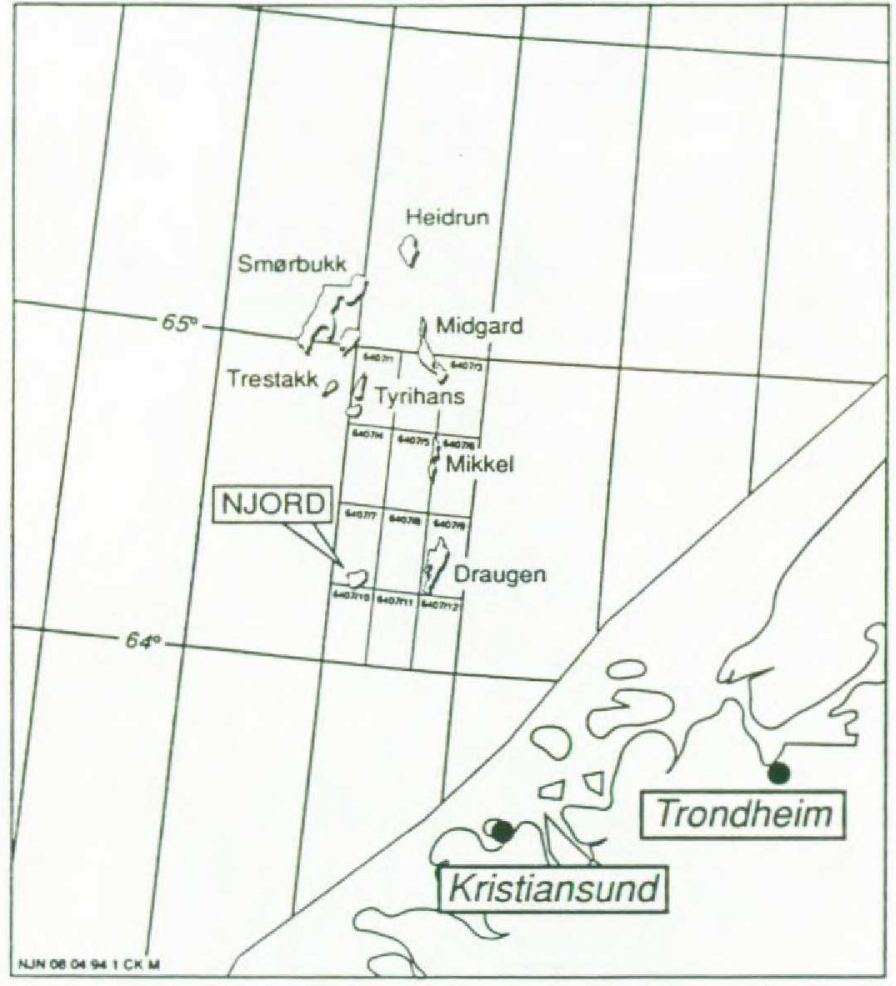

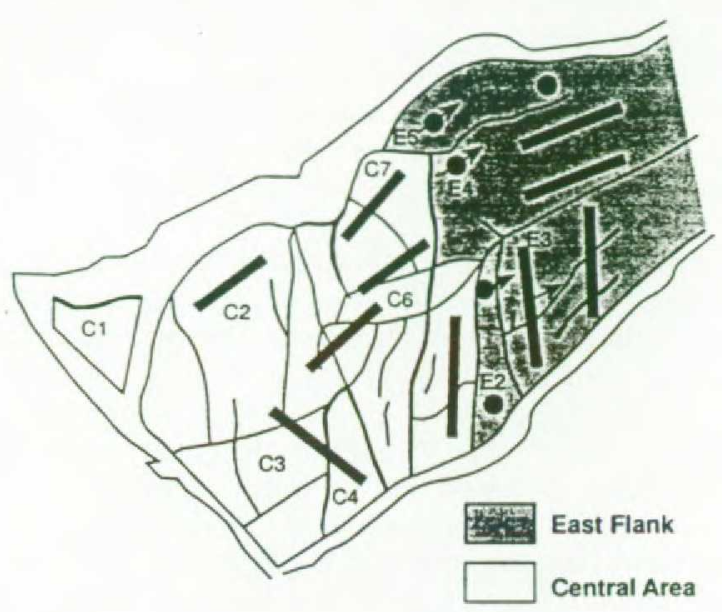

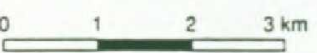

Figure 2 Njord Well Location Map.

Figure 1

Njord Field Location.

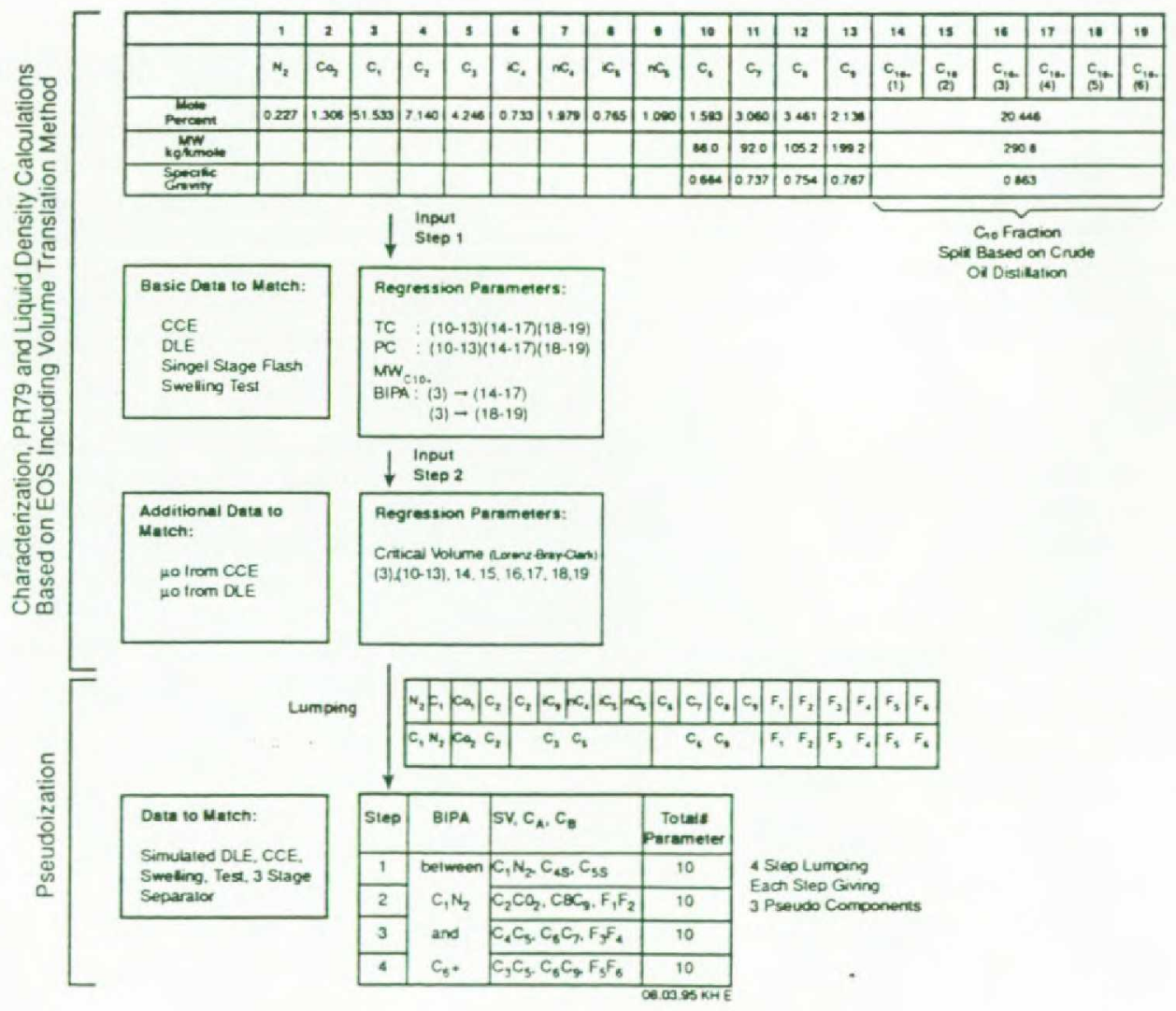

Figure 3

Characterisation and Pseudoisation 

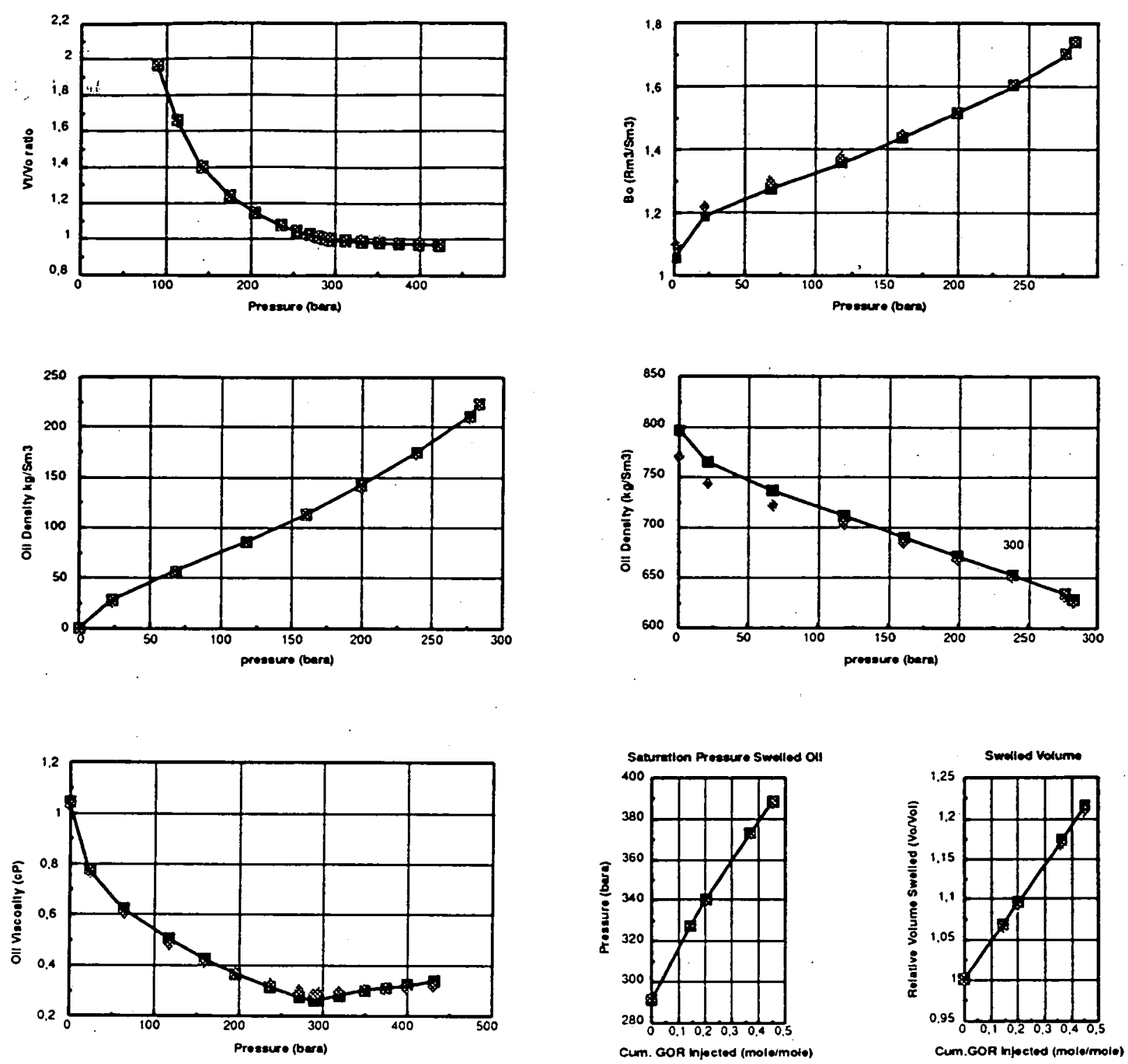

Figure $4 \quad$ Calculated and Experimental PVT data.

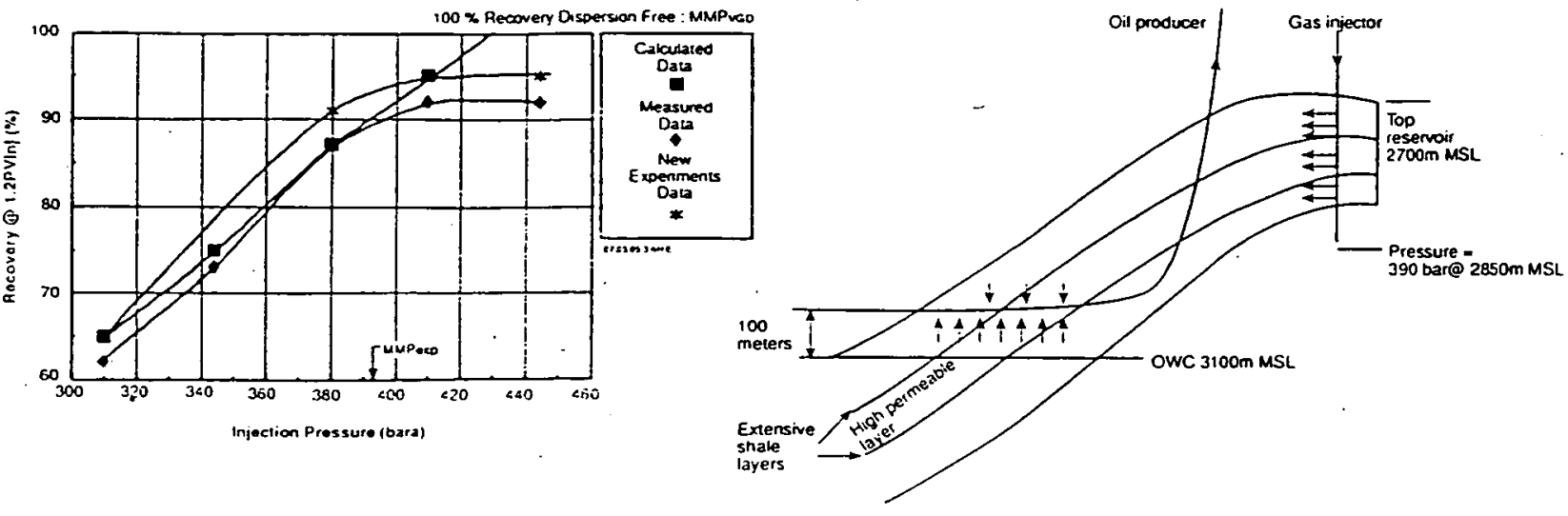



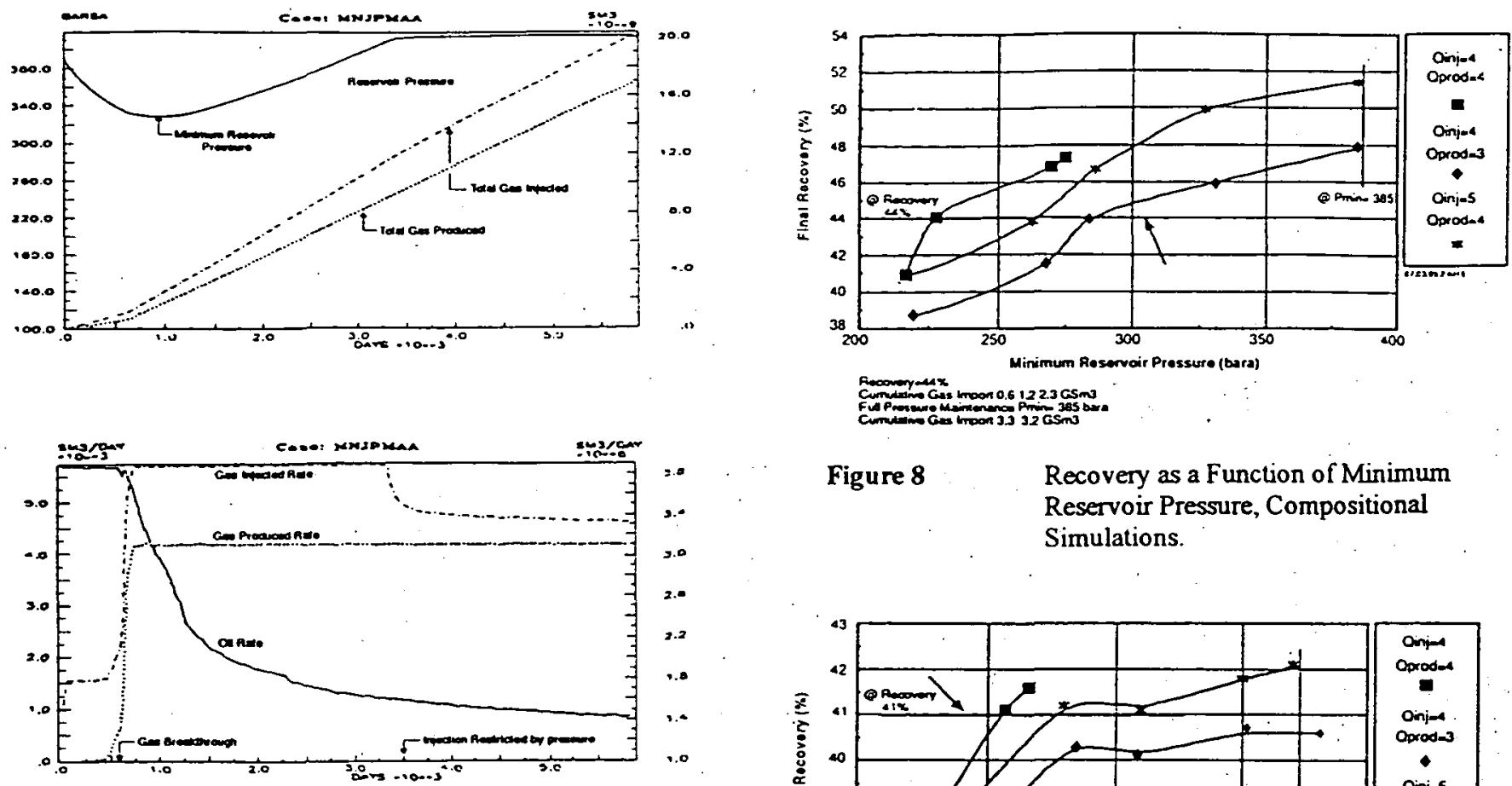

Figure 8

Recovery as a Function of Minimum Reservoir Pressure, Compositional Simulations.

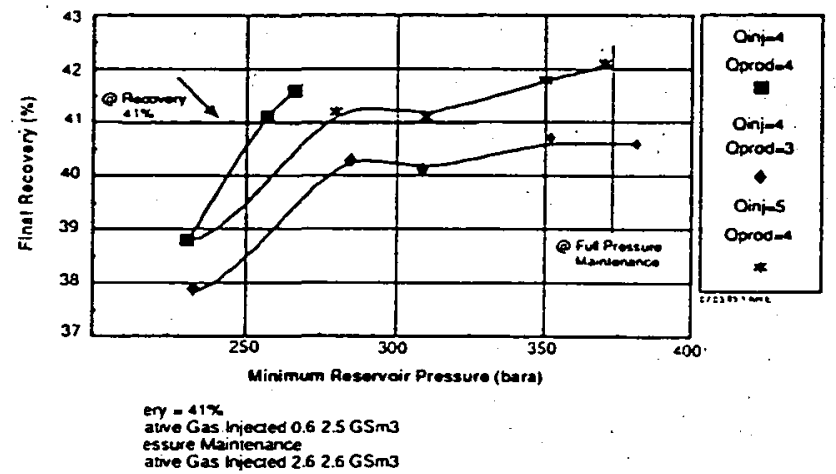

Figure 10 Recovery as a Function of Minimum Reservoir Pressure, Black Oil Simulations.

NJORD PRODUCTION PROFILES

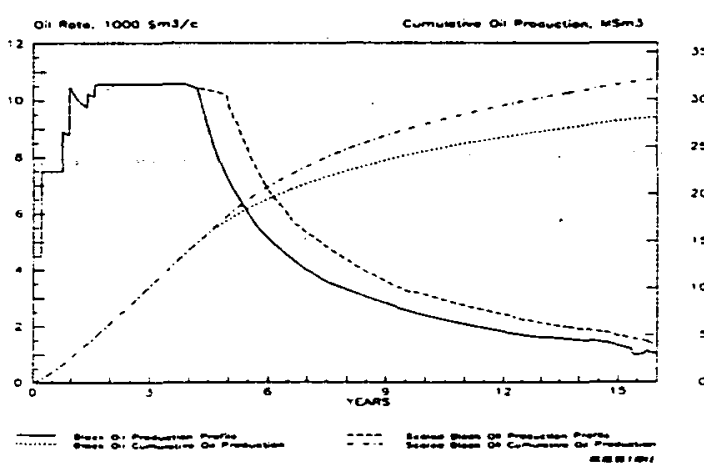

Figure 12 Unscaled and Scaled Full Field Profiles.

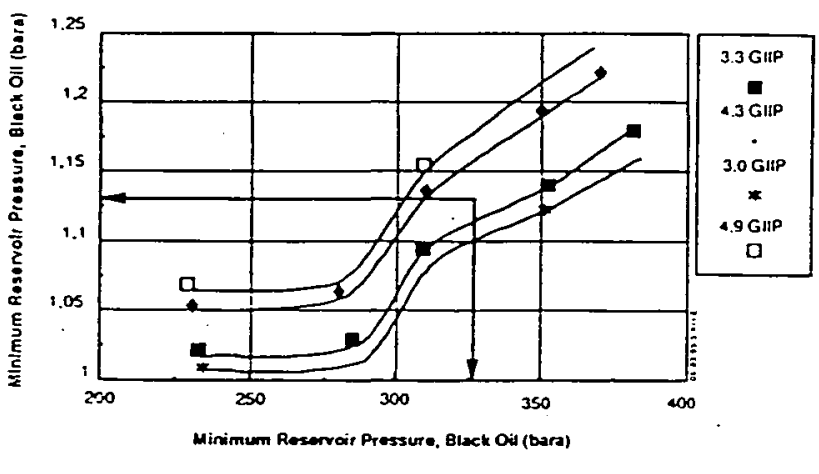

Figure 11 Scaling Functions

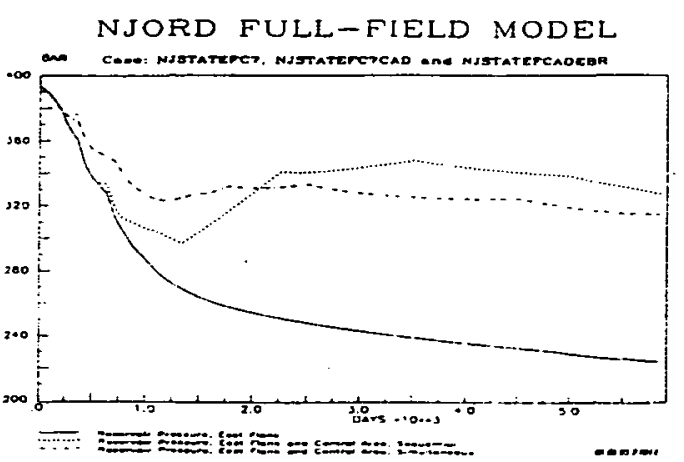

Figure 13 Average Reservoir Pressure, East Flank. 


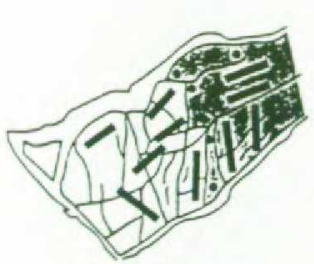

Dest Fiank

$\square$ Central Ares

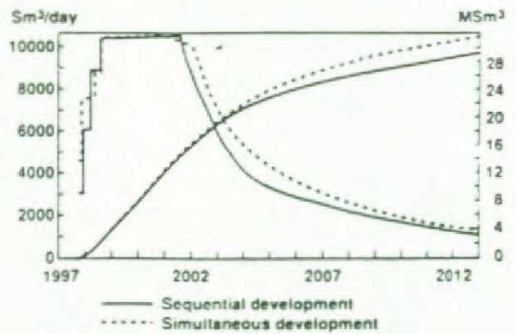

Increase in oil reserves with $8 \%$ due to higher reservoir pressure on the East Flank
Figure 14 Optimising Reservoir Management - Njord Field.

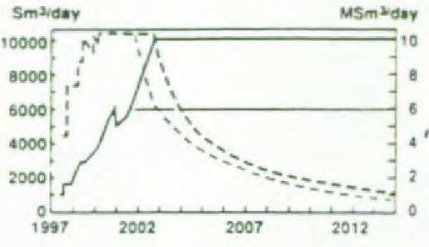

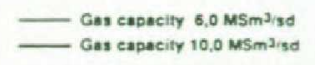

$\longrightarrow$ Increased plateau length due to increased gas capacity - Increase in oil reserves with $14 \%$ due to in reased gas capacity
Optimising Reservoir Management - Njord Field.
Stochastic Permeability, 3D Sector Model $X 7$ CROSS SECTION 1

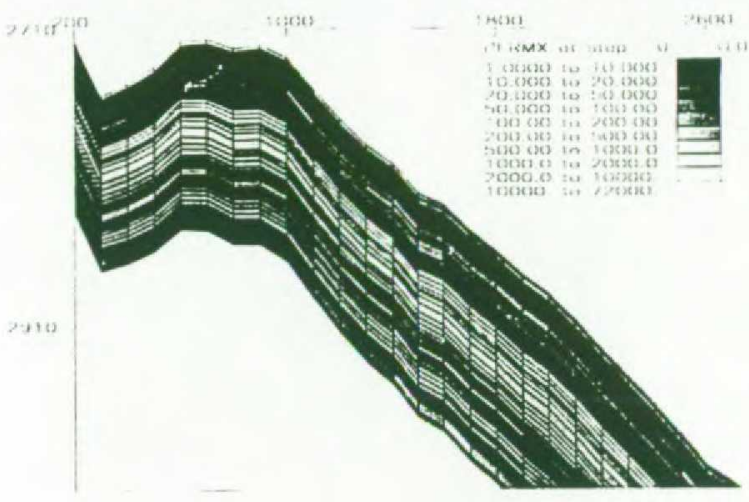

Figure 17

Cross Section Detailed Stochastic Model.
Figure 16

Full Field Black Oil and Compositional Simulation Results.

\begin{tabular}{|c|c|c|c|c|c|}
\hline Layer & $\begin{array}{c}\mathrm{h} \\
(\mathrm{m})\end{array}$ & $\begin{array}{c}\text { Porosity } \\
(\mathrm{frac})\end{array}$ & $\begin{array}{c}\mathrm{k}_{\mathrm{h}} \\
(\mathrm{mD})\end{array}$ & $\begin{array}{c}\mathrm{k}_{\mathrm{v}} \\
(\mathrm{mD})\end{array}$ & $\begin{array}{c}\text { NTG } \\
(\mathrm{frac} .)\end{array}$ \\
\hline 1 & 20.0 & 0.24 & 254 & 2.6 & 0.54 \\
\hline 2 & 19.8 & 0.23 & 311 & 78.0 & 0.77 \\
\hline 3 & 15.5 & 0.17 & 12 & 0.3 & 0.05 \\
\hline 4 & 21.8 & 0.24 & 2.371 & 0.6 & 0.70 \\
\hline 5 & 3.7 & 0.24 & 2.543 & 9.1 & 1.00 \\
\hline 6 & 15.0 & 0.23 & 528 & 4.4 & 0.82 \\
\hline 7 & 6.5 & 0.21 & 16 & 0.1 & 0.23 \\
\hline 8 & 4.0 & 0.21 & 264 & 7.8 & 0.69 \\
\hline 9 & 10.0 & 0.21 & 48 & 8.9 & 0.95 \\
\hline 10 & 15.0 & 0.24 & 246 & 66.0 & 0.98 \\
\hline 11 & 9.0 & 0.22 & 32 & 11.6 & 0.63 \\
\hline 12 & 11.0 & 0.21 & 75 & 12.7 & 0.91 \\
\hline & & & & & \\
\hline
\end{tabular}

\begin{tabular}{|l|c|c|}
\hline Model & $\begin{array}{c}\text { Recovery } \\
\text { factor }\end{array}$ & $\begin{array}{c}\text { Scaling } \\
\text { factor }\end{array}$ \\
\hline 12 layered, Comp & $49.3 \%$ & - \\
12 layered, BO & $41.5 \%$ & 1.19 \\
\hline 39 layered, Comp & $46.3 \%$ & - \\
39 layered, BO & $38.8 \%$ & 1.19 \\
\hline
\end{tabular}

Table 2 Scaling factor detailed reservoir model. 
